\title{
EFFECTS OF FINE FUEL MOISTURE AND LOADING ON SMALL SCALE FIRE BEHAVIOR IN MIXED-OAK FORESTS OF SOUTHEASTERN OHIO
}

\author{
John B. Graham ${ }^{1} \&$ Brian C. McCarthy²* \\ Department of Environmental \& Plant Biology, Ohio University, Athens, OH 45701-2979, USA \\ ${ }^{1}$ E-mail: john.b.graham.1@ohio.edu; 2E-mail mccarthy@ohio.edu \\ *Corresponding author \\ Address for Correspondence: \\ Brian C. McCarthy, 317 Porter Hall, Dept. of Env. \& Plant Biology, Ohio University \\ Athens, OH 45701-2979 USA; tel. 740-593-1615; fax. 740-593-1130 \\ email mccarthy@ohio.edu
}

\begin{abstract}
Multiple factors interact to influence fire behavior. While the interactions of fuel moisture and fuel loading in western coniferous communities are well understood, few studies have examined fire behavior in eastern deciduous forests. In order to accurately predict fire behavior in mixedoak forests, studies need to examine fire behavior in eastern deciduous forests. We conducted a fine-scale manipulative experiment to determine the specific effects that fine fuel moisture and load have on fire behavior in Ohio mixed-oak forests. Three fuel moisture levels (0, 4, and 15\% moisture), and five field-simulated fuel loads were burned in a $3 \times 5$ factorial experiment. Thermocolor pyrometers were used to measure maximum temperature at 5 and $30 \mathrm{~cm}$ as an indicator of fire behavior. Additionally, amount and percent of fuel burned were determined for each set of conditions. As expected, fires burned hotter with decreasing fuel moisture, and with increasing fuel load. Percent of fuel burned and mean temperature at 5 and $30 \mathrm{~cm}$ were positively correlated. Interactive effects were not observed. Temperatures were similar to those found in prior field studies in Appalachian Ohio. Controlled experiments such as this will likely prove useful in future efforts to link fuel conditions and fire behavior as landscape-scale effects are modeled. In particular, our results can be used to verify and calibrate fire behavior models in eastern mixed-oak forests.
\end{abstract}

Keywords: eastern deciduous forests, fire temperature, fuel dynamics, thermocolor pyrometers 


\section{INTRODUCTION}

Fire is a part of many ecosystems throughout the world. In North America, lightening strikes and American-Indianignited fires have served as ecological disturbances for millennia (e.g., Delcourt and Delcourt 1998; Pyne et al. 1996). Throughout the post-European settlement period, fire regimes were drastically altered. In particular, major shifts from extensive logging, mining, farming, and other intrusive land use activities occurred between about 1880 and 1930 in eastern North America (Abrams 1992; Brose et al. 2001). Following forest clearing, standreplacing fires in logging slash more frequently burned widespread areas. These fires were entirely different from the low intensity fires formerly found in the region (Brose et al. 2001). The specific characteristics of fire regimes are still being studied and debated in many areas of the United States, especially in Appalachian hardwood forests (e.g., Clark et al. 1996; Clark 1997).

Although the specific correlation between fire and forest composition and structure is still under debate for many ecosystems, land managers are beginning to use fire for ecosystem management in regions throughout the United States. In eastern deciduous forests, fire can have considerable short-term impacts on the herbaceous layer, understory vegetation, and forest regeneration (Hutchinson 2004; Hutchinson et al. 2005); however, the impact to the overstory canopy is usually minimal (Franklin et al. 1997). Furthermore, fire can strongly alter the fuel composition and structure in many forests (e.g., Tveten and Fonda 1999; Brown et al. 2004; Pyne et al. 1996). Inversely, fuel composition, structure, and moisture levels can strongly impact fire behavior.

Fuel moisture content and the amount of fuel present ('fuel loading') both influence fire behavior. The relationship between fire behavior and fuel loading or fuel moisture has been studied primarily in western systems (e.g., Miller and Urban 2000; Sapsis and Kauffman 1991; Williamson and Agee 2002), or in coniferous systems in other areas of the world (e.g., Bessie and Johnson 1995; McRae 1999). The effect of prescribed fire on fuels and fire behavior has not yet been well studied in eastern forests, certainly not when compared to western systems.

In eastern deciduous forests, fuel dynamics and the resulting fire behavior are dramatically different from what has been studied in western coniferous systems. High productivity is balanced by high moisture- and temperature- driven rates of decomposition in eastern forests. Fuel tends to decompose much faster than in western systems, where frequent drought causes low soil moisture, allowing fuels to accumulate over decades or centuries. For example, Onega and Eickmeier (1991) reported fuel half-lives an order of magnitude shorter in eastern forests compared to western forests. In fact, it is usually only the fine fuels which are consumed in most eastern deciduous forest fires due to their ability to lose moisture content rapidly enough.

Much of the eastern deciduous forest is located in topographically diverse terrain. Southeastern Ohio is a deeply dissected region of the Low Hills Belt of the Unglaciated Allegany Plateau (Braun 1950). Sedimentary bedrock is the basis for narrow ravines, short hills, and variable slope aspects (Forsyth 1970). Highly dissected landscapes lead to widely varied microclimates (Wolfe et al. 1949) and produce drastically different fuel conditions depending on slope position, percent slope, and slope aspect. Fuel load and fuel moisture can vary immensely within short spatial spans $(<100 \mathrm{~m})$, depending on specific site variables including topography and 
microclimate (e.g., Pyne et al. 1996; McCarthy et al. 2001).

Franklin et al. (1997) examined fire temperature patterns as a function of litter and duff biomass, horizontal and vertical fuel structure, and topographic variation in oak forests of Kentucky. They found that smallscale topography had a greater influence on fire characteristics than either fuel loading or fuel structure (Franklin et al. 1997), but their study took place across $30 \times 140 \mathrm{~m}$ 'macroplots' with substantial inherent variation of both topography and fuel composition. Furthermore, Franklin et al. (1997) did not directly examine the impact of differing fuel moisture levels on fire behavior.

In order to determine the specific correlation between fuel load and fuel moisture on fire behavior, an analysis of fuel conditions and fire behavior must be performed under controlled conditions. This will eliminate the topographic variation and differences in fuel composition inherent to in situ studies. We conducted experimental burns in a common garden to examine the characteristics of fire behavior across the range of fuel conditions found in eastern deciduous forests. We controlled the fuel load and fuel moisture within $1 \mathrm{~m}^{2}$ plots and used pyrometer temperature as a surrogate for fire behavior. Our results may ultimately be used, probably in conjunction with additional data, to verify and calibrate fire behavior models in eastern mixed-oak forests.

Fire behavior is linked to fuel load and fuel moisture. We hypothesize that, 1) fuel load and fuel moisture will have a strong impact on the maximum and mean temperatures attained in experimental burns at both 5 and $30 \mathrm{~cm}$ above the leaf litter, 2) the percent of fuel burned will be strongly related to the fuel load and fuel moisture levels, and 3) the percent of fuel burned will be strongly correlated to the flame temperature at 5 and 30 $\mathrm{cm}$.

\section{METHODS}

\section{Fuel collection and manipulation}

Fuels were collected from Zaleski State Forest $\left(39^{\circ} 35^{\prime} 5\right.$ ? N 82 ${ }^{\circ} 37^{\prime} 0$ ?W) in Vinton County, Ohio on 24 March 2005. Three classes of fuel were collected: litter, 1-hr fuels (0-6 mm diameter), and 10-hr fuels (6-25 mm diameter). Fuels were placed in large paper bags and dried at $80{ }^{\circ} \mathrm{C}$ for 72 hours in a Grieve SB-350 drying oven. Dried fuel samples were hand-sorted by placing all materials from each class into large plastic garbage bins. Each bin was thoroughly mixed in order to homogenize fuel composition across the sample. Fuels were bagged in plastic following sorting to ensure that no change in fuel moisture occurred from ambient humidity levels in the laboratory.

Five levels were chosen to represent the range of fuel load estimates calculated from data collected during 2004 in southeastern Ohio mixed-oak forests (J. Graham and B. McCarthy, in review). The specific values were chosen to represent fuel loading at the 10, 30, 50, 70, and 90 percentiles for realistic estimates of leaf litter, 1-hr, and 10-hr fuel load (Table 1). Fuels were separated into bags each containing enough material to represent $1 \mathrm{~m}^{2}$ at one of these five fuel-loading levels.

Fuel moisture levels were manipulated in order to measure the effects of fuel moisture on fire behavior. Three different levels of fine-fuel moisture were chosen to represent a) completely dry fuels ( $0 \%$ fuel moisture), b) the minimum allowable fuel moisture in typical southern Ohio fire prescriptions (4\% fuel moisture), and c) the maximum allowable fuel moisture in the same fire prescriptions (15\% fuel moisture) (Mike Bowden, pers. comm.; Iverson et al. 2004). Moisturemanipulations were conducted by adding a specific quantity of distilled water to each 
Table 1. Fuel load estimates used in experimental burns. All fuel amounts are given in grams, and were calculated for $1 \mathrm{~m}^{2}$ plots based on the $10,30,50,70$, and $90^{\text {th }}$ percentiles of actual fuel load estimates $\left(\mathrm{Mg} \cdot \mathrm{ha}^{-1}\right)$ from southeastern Ohio. Amount of distilled water $(\mathrm{mL})$ added to each treatment to produce $4 \%$ and $15 \%$ fuel moistures is given in the last two columns.

\begin{tabular}{rrrrrrrr}
\hline \hline Treatment & $\begin{array}{r}\text { Fuel } \\
\text { percentile }\end{array}$ & Litter & $\mathbf{1 - h r}$ & $\mathbf{1 0 - h r}$ & Total & $\begin{array}{r}\text { Water } \\
\mathbf{( 4 \% )}\end{array}$ & $\begin{array}{r}\text { Water } \\
\mathbf{( 1 5 \% )}\end{array}$ \\
FL1 & 10 & 328 & 87 & 61 & 476 & 19 & 72 \\
FL2 & 30 & 471 & 213 & 178 & 862 & 35 & 129 \\
FL3 & 50 & 613 & 330 & 238 & 1181 & 47 & 177 \\
FL4 & 70 & 781 & 455 & 356 & 1592 & 64 & 239 \\
FL5 & 90 & 1071 & 702 & 536 & 2309 & 92 & 346 \\
\hline
\end{tabular}

Figure 1. Images from trial burns. a) Treatments prior to burning, b-d) high fuel load, low moisture treatment from ignition to near complete combustion - elapsed time is approximately 1 min, e) high fuel load, low moisture (black arrow) unit next to high fuel load, high moisture unit (white arrow) - ignition was at the same time f) post-burn tags and remaining fuel.

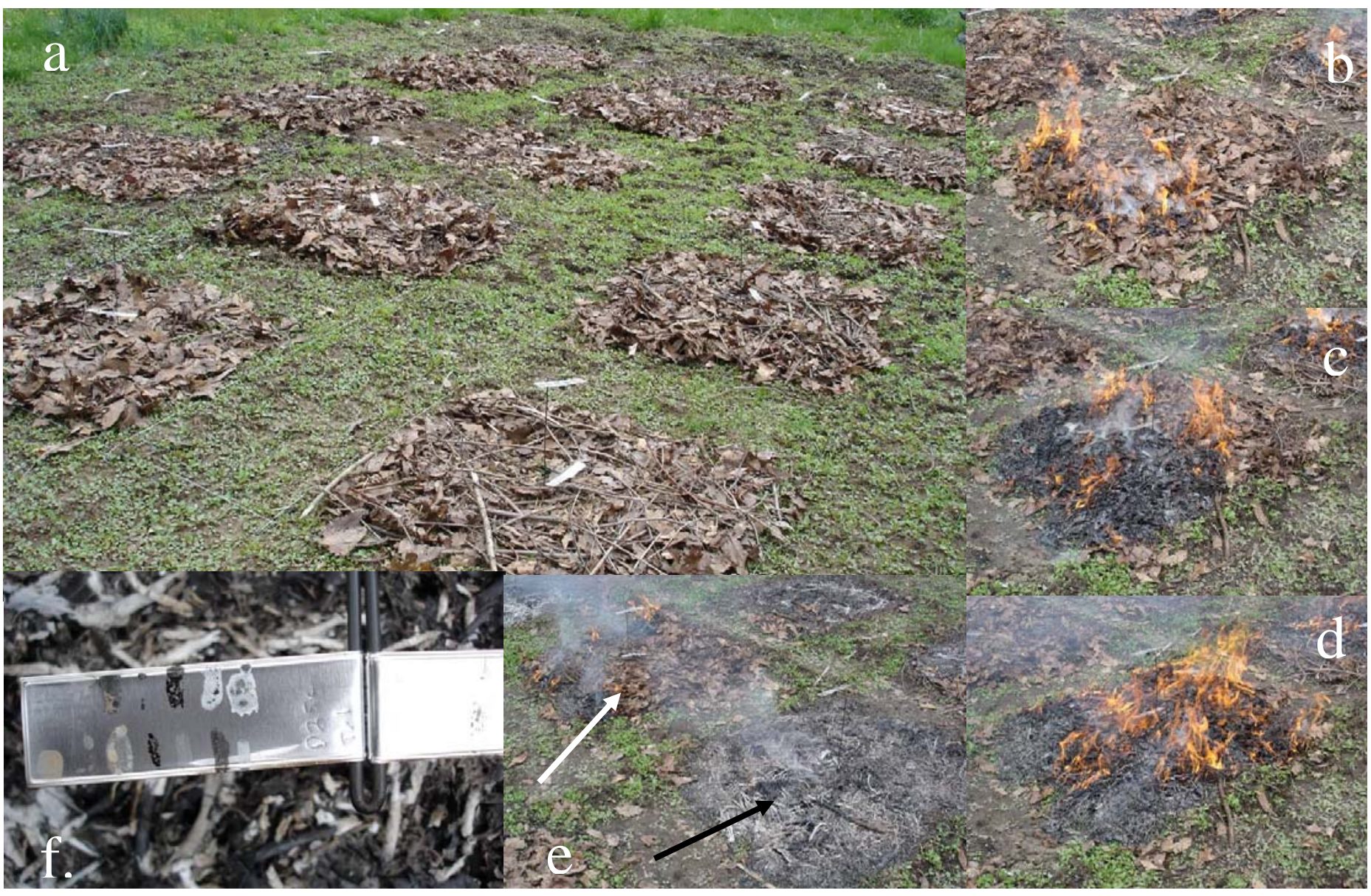


specific weight of dry fuel (Table 1). The hydrated fuels were then sealed in plastic bags, shaken, and allowed to imbibe the water for at least 24 hrs. This allowed the fuel moisture levels to increase to and stabilize at the desired levels.

\section{Experimental burn setup and conditions}

Combinations of five fuel loads and three fuel moisture levels were arranged in three replicated, $3 \times 5$ factorial design, 'common garden' experimental burns (Figure 1a). Each set of conditions (fuel-loading level $\times$ fuelmoisture level) was replicated in a $1 \mathrm{~m}^{2}$ plot. The experimental burn area was tilled in the fall prior to the burns, and raked immediately before plot establishment. Re-hydrated fuels were spread evenly throughout the $1 \mathrm{~m}^{2}$ plot, compacted by hand to reduce fuel 'fluff,' and then lit on fire. Specific locations for each combination were chosen randomly within a 3 $\times 5$ quadrat grid. Locations of each set of treatments varied between each of the burns. Experimental plots were separated from each other by $0.5 \mathrm{~m}$ of unburnable material.

Three experimental burns were conducted; one on 28 April 2005, and the remaining two on 2 May 2005. Weather conditions (Table 2) were within the prescription parameters for southeastern Ohio. We ignited the fires with a propane torch on the upwind corner of each 1 $\mathrm{m}^{2}$ quadrat. Most burns self-extinguished within 10 min (Figure 1b-d). High moisture, high fuel-load burns smoldered and took much longer to extinguish (up to $30 \mathrm{~min}$ in some cases; Figure 1e). Some fuel $\times$ moisture combinations were difficult to ignite, or the fire barely carried through the quadrat.

\section{Fuel Data Collection and Analysis}

Temperature data was collected from the center of each $1 \mathrm{~m}^{2}$ quadrat using thermocolor pyrometers (Figure 1f). Each pyrometer consisted of a JIM-GEM ${ }^{\circledR}$ aluminum tag onto which we painted fourteen spots of Tempilaq ${ }^{\circ} \mathrm{G}$ temperature indicating liquid paint (Big Three Industries Inc., Tempil ${ }^{\circ}$ Division, South Plainfield, NJ). Thermocolor pyrometers were compared to HOBO dataloggers in Ohio mixed-oak forests (Iverson et al. 2004) in order to determine their efficacy when compared to thick thermocouples. Iverson et al. (2004) found that pyrometers provided a reliable estimate of maximum fire temperature at a fraction of the cost of electronic data-collection equipment. These results were supported by Kennard et al. (2005) who indicate that metal pyrometers (as opposed to tile pyrometers) do an adequate job of measuring mean and maximum temperatures when using thick thermocouples as the basis of comparison. Importantly, neither pyrometers nor thermocouples measure the actual temperature of fire; rather, these devices measure the maximum temperature that they themselves attain during a fire (Kennard et al. 2005).

Table 2. Conditions for experimental burns. Burn number, date, average wind speed $\left(\mathrm{km} \cdot \mathrm{hr}^{-1}\right)$, maximum wind gusts $\left(\mathrm{km} \cdot \mathrm{hr}{ }^{-1}\right)$, temperature $\left({ }^{\circ} \mathrm{C}\right)$, and relative humidity (\%) are given for the three different burns.

\begin{tabular}{rrrrrr}
\hline \hline Burn & $\begin{array}{r}\text { Date } \\
\text { 28-Apr-05 }\end{array}$ & $\begin{array}{r}\text { Wind } \\
\text { speed }\end{array}$ & $\begin{array}{r}\text { Wind } \\
\text { gusts }\end{array}$ & $\begin{array}{r}\text { Temp } \\
\text { Relative } \\
\text { humidity }\end{array}$ \\
1 & 3.8 & 7.7 & 16.1 & $28-35$ \\
2 & 2-May-05 & 4.8 & 8.2 & 9 & 42 \\
3 & 2-May-05 & 3.2 & 4.9 & 9.9 & 35 \\
\hline
\end{tabular}


Furthermore, Kennard et al. (2005) point out that the heat budget of the recording device directly influences the measured temperature number. As such, thin aluminum pyrometers (e.g., JIM-GEM ${ }^{\circledR}$ tags) should provide a decent estimate of temperature. Iverson et al. (2004) documented maximum fire temperature in mixed-oak fires in southeastern Ohio up to approximately 450 ${ }^{\circ} \mathrm{C}$, with the majority burning no higher than $300{ }^{\circ} \mathrm{C}$. The minimum temperature detectable by Tempilaq ${ }^{\circ} \mathrm{G}$ is $79^{\circ} \mathrm{C}$, thus we chose paints that melt within this $79-450{ }^{\circ} \mathrm{C}$ range. The specific temperatures that we chose were: 79 , 93, 107, 135, 163, 191, 218, 246, 274, 316, 343, 371, 399, and $427^{\circ} \mathrm{C}$. Aluminum melts at $660{ }^{\circ} \mathrm{C}$, so any melted tags indicated that flame temperatures exceeded this temperature.

Four pyrometers were used in each treatment unit. Pyrometers were centered in each plot, two being suspended $5 \mathrm{~cm}$ above the litter layer, and the other two being suspended $30 \mathrm{~cm}$ above the litter layer (Figure 2). Using four pyrometers in each quadrat allowed for measurement redundancy and for comparisons between the surface temperature $(5 \mathrm{~cm})$ and the temperature produced above the surface $(30 \mathrm{~cm})$. Pyrometers were suspended from 8 gauge wire holders which were bent to allow the tags to hang horizontally, away from any disturbance caused by the main wire (Figure 2).

Pyrometers were removed from the plots immediately following burning. Thermocolor paint spots were examined in the lab, and scored as 'melted' if any portion of the spot was melted or heavily charred (Drewa et al. 2002; Iverson et al. 2004). Following fire extinction, all unburned fuel was collected from each $1 \mathrm{~m}^{2}$ quadrat, dried in the lab for 72 hrs, and weighed. We replicated the experiment three times using fresh fuel and pyrometers each time. This allowed for calculations of variance under each combination of loading vs. moisture conditions. Maximum temperature at 5 and $30 \mathrm{~cm}$, mean temperature at 5 and $30 \mathrm{~cm}$, unburned fuel mass, burned fuel mass, and percent burned fuel mass were analyzed using factorial analysis of variance (Zar 1999) in NCSS (Hintze 2001). Unburned and burned fuel mass were transformed using a naturallog transformation to improve normality (Zar 1999). Percent burned fuel mass was transformed using an angular transformation to increase normality (Zar 1999).

\section{RESULTS}

Maximum and mean temperatures both ranged $0-660{ }^{\circ} \mathrm{C}$ at $5 \mathrm{~cm}$ above the leaf litter (Figure $3 \mathrm{a}$ and $\mathrm{b}$ ). The highest temperatures were recorded in Fuel Load 5 (FL5; representing a fuel load of approximately 23.09 Mg. ha ${ }^{-1}$ ), and decreased with increasing moisture. Fuel Load 4 (FL4; representing 15.92 $\mathrm{Mg} \cdot \mathrm{ha}^{-1}$ ) exhibited slightly lower temperatures than FL5 at lower fuel moistures, and equivalent temperatures at higher fuel moistures. Temperatures for Fuel Load 3 (FL3; representing $11.81 \mathrm{Mg} \cdot \mathrm{ha}^{-1}$ ) were equivalent to FL4 at low fuel moistures, but lower at 4 and $15 \%$ fuel moisture. Fuel Loads 2 (FL2; representing $8.62 \mathrm{Mg} \cdot \mathrm{ha}^{-1}$ ) and 1 (FL1; representing $4.76 \mathrm{Mg} \cdot \mathrm{ha}^{-1}$ ) were equivalent to each other, crossing at the medium fuel moisture level and were both lower than FL3. The same patterns were recorded at $30 \mathrm{~cm}$ above the leaf litter, where maximum and mean temperatures both ranged from ambient to 274 ${ }^{\circ} \mathrm{C}$ (Figure 3c and d). However, FL4 actually exhibited higher temperatures than FL5 at 4\% and $15 \%$ fuel moisture. 
Figure 2. Wire holders and aluminum tags for thermocolor pyrometers. Two pyrometers were suspended $5 \mathrm{~cm}$ above the leaf litter. Two additional pyrometers were suspended $30 \mathrm{~cm}$ above the leaf litter. Pyrometers were suspended from a jig made out of 8 ga wire, and placed in the ground at the center of each $1 \mathrm{~m}^{2}$ experimental treatment unit.

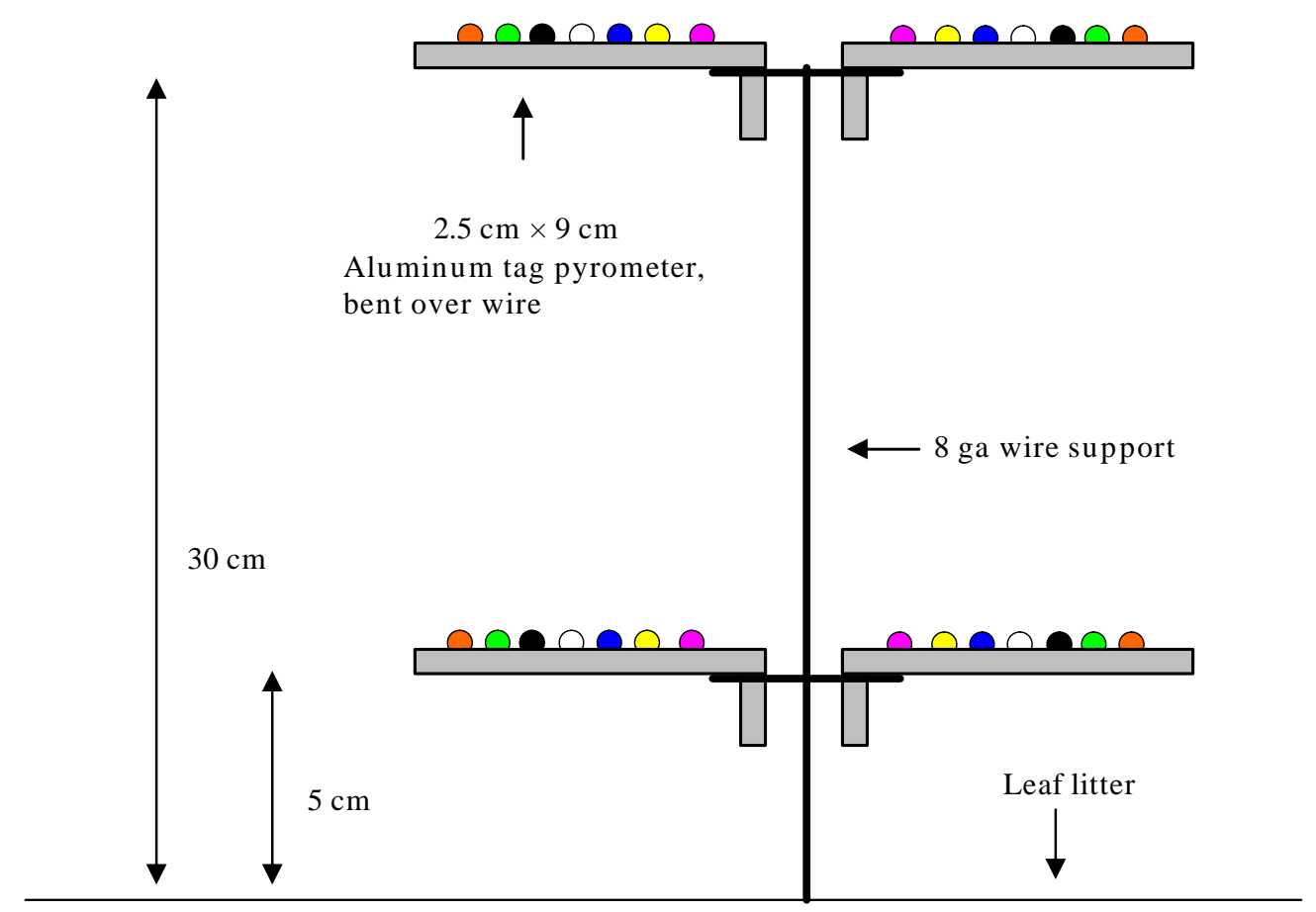

Percent of fuel burned ranged from $6 \%$ to $97 \%$ while the mean percent of fuel burned ranged from $29 \%$ to $95 \%$ (Figure 4). FL5 had the highest percentage burned across the fuel moisture levels. The percentage of fuel burned decreased in all cases based on increasing fuel moisture and decreasing fuel load. The lowest percentage (6\%) of fuel burned was found in FL1 at 15\% moisture.

Burning parameters varied significantly with respect to fuel moisture and fuel load. Analysis of variance indicated that differences in fuel moisture and fuel load were significantly related to maximum temperature at 5 and $30 \mathrm{~cm}$, mean temperature at 5 and 30 $\mathrm{cm}$, unburned fuel mass, burned fuel mass, and percent burned fuel mass (Table 3). The interaction between moisture and fuel load was not statistically significant (Table 3). Mean temperature at both 5 and $30 \mathrm{~cm}$ was positively correlated to percent of fuel burned (Figure 5): the Spearman's rank correlation was $0.815(P<0.0001)$ at $5 \mathrm{~cm}$ and $0.726(P$ $<0.0001)$ at $30 \mathrm{~cm}$.

\section{DISCUSSION}

The experimental burn results indicate that fire behavior (as measured by temperature and amount of fuel burned) will depend on the amount of fuel present and on the fuel moisture level. 
Figure 3. Maximum and mean temperatures vs. fuel moisture level. The two rows are presented with different scales on the y-axis. Fuel load levels represent $1 \mathrm{~m}^{2}$ of forest floor at the $10,30,50,70$, and $90^{\text {th }}$ percentiles (approximately 4.76, 8.62, 11.81, 15.92, and $23.09 \mathrm{Mg} \cdot \mathrm{ha}^{-1}$ ) of estimates of litter, 1-hr, and 10-hr fuels in southeastern Ohio mixed-oak forests. Fuel moisture levels refer to percent moisture by weight. Error bars represent the standard error of the mean.

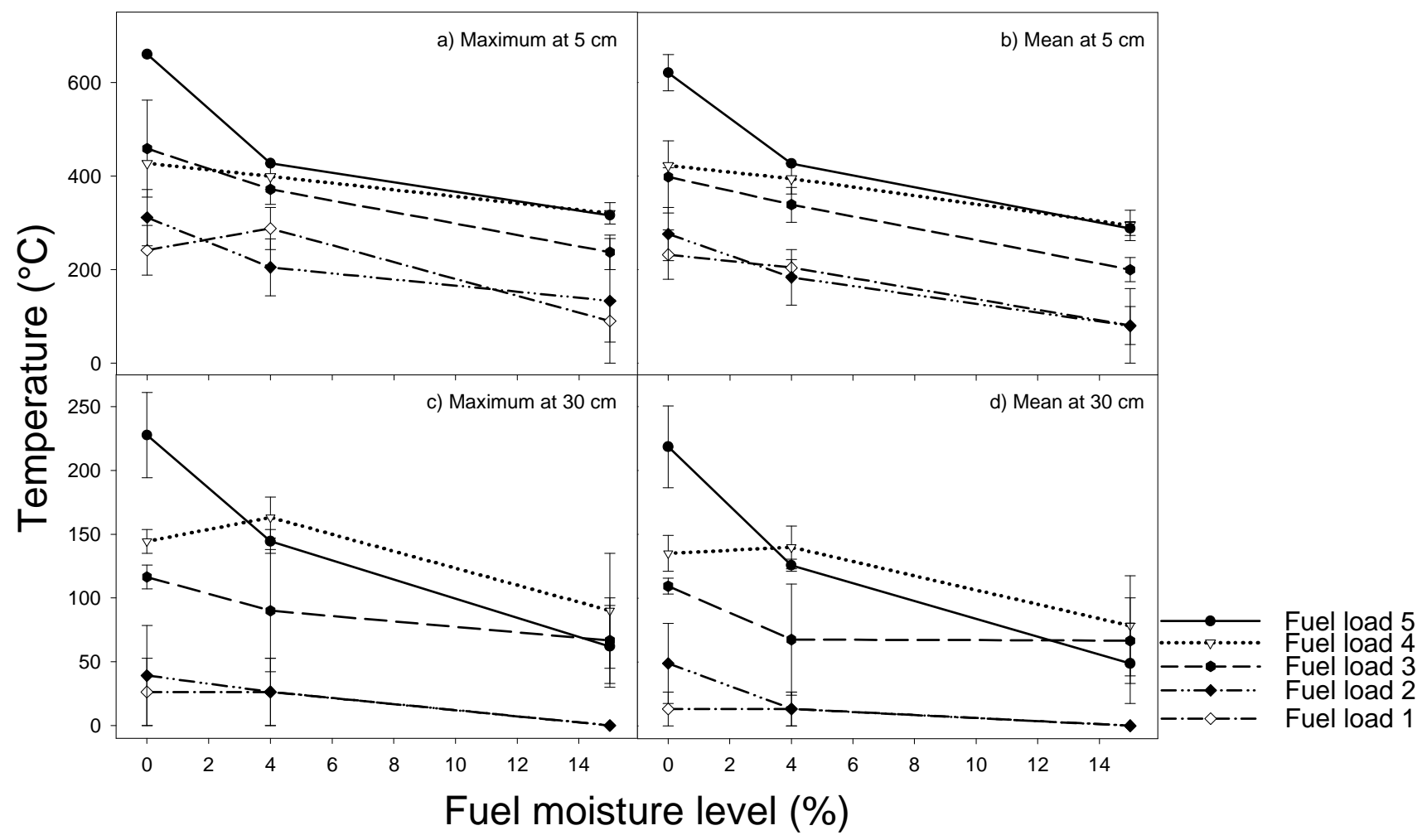

Within the parameters of our experiment, fuel moisture and fuel load did not have interactive effects on fire behavior. However, our personal observation during the experimental burns was that other measurements of fire behavior may have exhibited an interactive effect. Total burn time (2-20 minutes), smoke production, and flame length $(20-50 \mathrm{~cm})$ all seemed to vary depending on both the fuel load and moisture content, possibly interactively. In some cases, these variables may be more ecologically important than fire temperature.

Fuel moisture and fuel load combinations were strongly related to all measurements of fire behavior. Increasing fuel moisture and decreasing fuel load decreased maximum and mean temperatures at both 5 and $30 \mathrm{~cm}$ above the litter layer. Similarly, a higher percentage of fuel burned in heavier fuel loads (likely due to longer smoldering times with moist fuels) and in dryer fuel conditions. Percent of fuel burned was also positively correlated to mean temperatures achieved at 5 and $30 \mathrm{~cm}$ above the litter. This correlation was slightly stronger at $5 \mathrm{~cm}$ than at $30 \mathrm{~cm}(r=0.82$ vs. $r$ $=0.73$ ). The correlation between temperature and percent of fuel burned indicates that temperature is a good predictor of some characteristics of fire behavior. Additional measures of fire behavior would be ideal but are not always possible in the field. 
Figure 4. Percent of fuel burned vs. fuel percent moisture in experimental burning treatments. Fuel load levels $1-5$ represent $1 \mathrm{~m}^{2}$ of forest floor at the 10, 30, 50, 70, and $90^{\text {th }}$ percentiles of estimates of litter, 1-hr, and 10-hr fuels in southeastern Ohio mixedoak forests (for more details, see Table 1). Error bars represent the standard error of the mean.

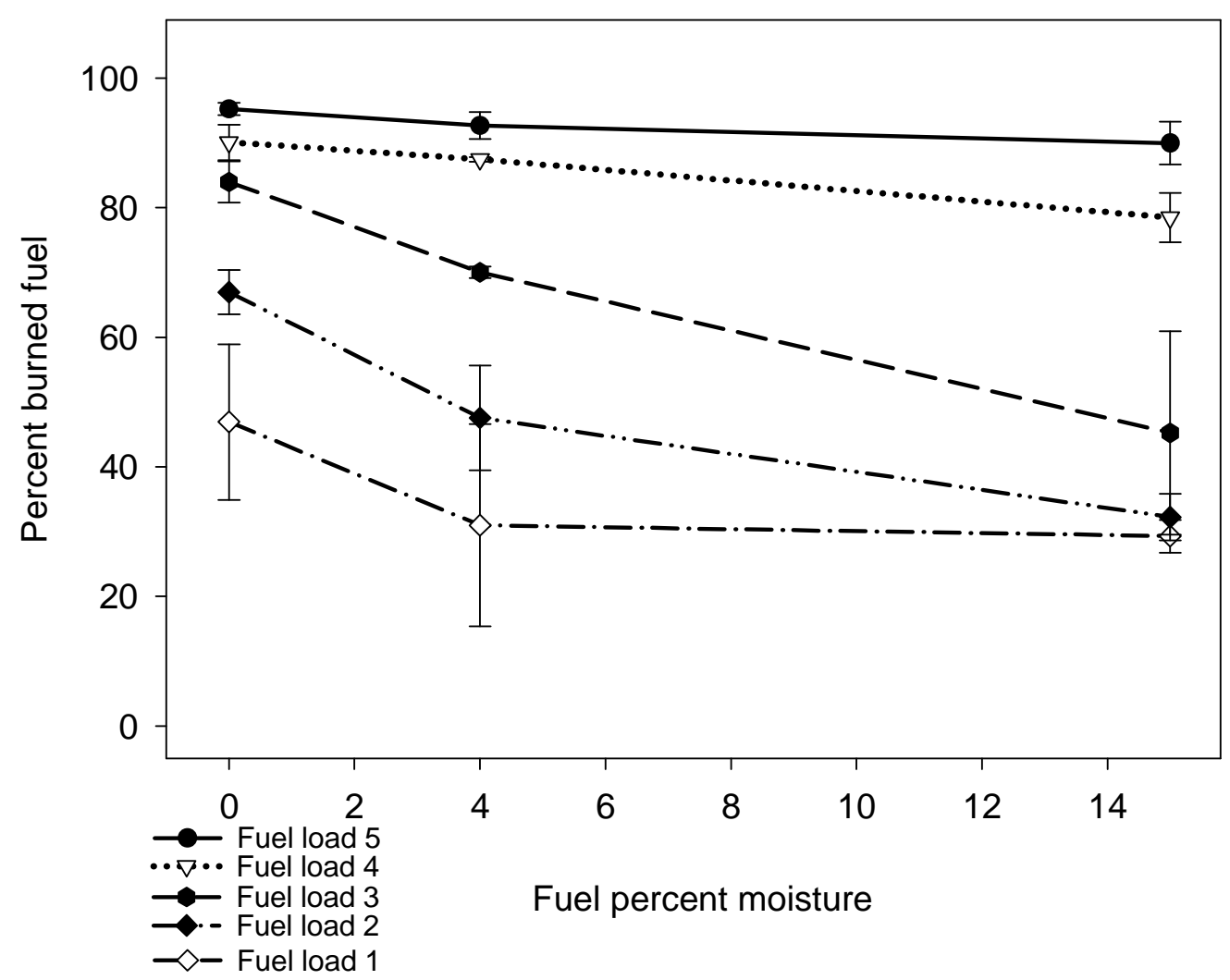

Thus, when other measurements are not available or practical, fire temperature can provide an acceptable estimate of fire behavior. In addition, our experiment most closely mimics a typical headfire; future research might explore alternate modes of burning such as backfires.

Iverson et al. (2004) found that temperatures rarely exceeded $300{ }^{\circ} \mathrm{C}$ during prescribed fires in nearby mixed-oak forests, with occasional temperatures up to $450{ }^{\circ} \mathrm{C}$. In our study, $24 \%$ of the treatment units had a maximum recorded temperature of $427{ }^{\circ} \mathrm{C}$. Of those treatments, $36 \%$ had temperatures above $660{ }^{\circ} \mathrm{C}$ (the melting point of aluminum). These treatment units were primarily in low moisture, high fuel load quadrats. High fuel loads tend to be found at low positions along northeast-facing slopes (McCarthy et al. 2001), while higher temperatures and dryer fuels tend to be located high on southwest-facing slopes (Pyne et al. 1996). Sites with the combination of extremely high fuel load and very dry fuels are relatively rare in mixed-oak forests of southeastern Ohio. It is possible that Iverson et al. (2004) may not have had any sampling units exhibiting this specific combination of high fuel load and low fuel moisture. The high temperaturess recorded in our results probably represent the terminus of a continuum, while Iverson et al. (2004) did not 
Table 3. ANOVA tables for factorial analysis of experimental burns. Tables for maximum temperature at $5 \mathrm{~cm}$, mean temperature at $5 \mathrm{~cm}$, unburned fuel mass (g), burned fuel mass (g), and percent burned fuel mass are presented.

\begin{tabular}{|c|c|c|c|c|c|c|}
\hline Source term & DF & $\begin{array}{l}\text { Sum of } \\
\text { squares }\end{array}$ & $\begin{array}{r}\text { Mean } \\
\text { square }\end{array}$ & F-Ratio & Prob Level & $\begin{array}{r}\text { Power } \\
\text { (Alpha }=0.05)\end{array}$ \\
\hline \multicolumn{7}{|l|}{ Maximum temperature } \\
\hline Moisture & 2 & 304448 & 152224 & 16.44 & $<0.0001$ & 0.99 \\
\hline Fuel & 4 & 454043 & 113511 & 12.26 & $<0.0001$ & 0.99 \\
\hline Moisture $\times$ fuel & 8 & 85822 & 10728 & 1.16 & 0.355 & 0.44 \\
\hline $\mathrm{S}$ & 30 & 277707 & 9257 & & & \\
\hline Total (Adjusted) & 44 & 1122021 & & & & \\
\hline Total & 45 & & & & & \\
\hline \multicolumn{7}{|l|}{ Mean temperature } \\
\hline Moisture & 2 & 308645 & 154322 & 26.02 & $<0.0001$ & 0.99 \\
\hline Fuel & 4 & 512092 & 128023 & 21.59 & $<0.0001$ & 1.00 \\
\hline Moisture $\times$ fuel & 8 & 45756 & 5719 & 0.96 & 0.481 & 0.36 \\
\hline $\mathrm{S}$ & 30 & 177901 & 5930 & & & \\
\hline Total (Adjusted) & 44 & 1044394 & & & & \\
\hline Total & 45 & & & & & \\
\hline \multicolumn{7}{|l|}{ Unburned fuel mass } \\
\hline Moisture & 2 & 4.171 & 2.0853 & 16.52 & $<0.0001$ & 0.99 \\
\hline Fuel & 4 & 5.679 & 1.4198 & 11.25 & $<0.0001$ & 0.99 \\
\hline Moisture $\times$ fuel & 8 & 0.590 & 0.0737 & 0.58 & 0.783 & 0.22 \\
\hline $\mathrm{S}$ & 30 & 3.786 & 0.1262 & & & \\
\hline Total (Adjusted) & 44 & 14.226 & & & & \\
\hline Total & 45 & & & & & \\
\hline \multicolumn{7}{|l|}{ Burned fuel mass } \\
\hline Moisture & 2 & 1.324 & 0.6620 & 4.54 & 0.019 & 0.73 \\
\hline Fuel & 4 & 40.262 & 10.0656 & 69.03 & $<0.0001$ & 1.00 \\
\hline Moisture $\times$ fuel & 8 & 1.158 & 0.1447 & 0.99 & 0.462 & 0.37 \\
\hline $\mathrm{S}$ & 30 & 4.375 & 0.1458 & & & \\
\hline Total (Adjusted) & 44 & 47.119 & & & & \\
\hline Total & 45 & & & & & \\
\hline \multicolumn{7}{|l|}{ Percent burned fuel mass } \\
\hline Moisture & 2 & 0.452 & 0.2261 & 11.53 & $<0.001$ & 0.99 \\
\hline Fuel & 4 & 2.822 & 0.7055 & 35.96 & $<0.0001$ & 1.00 \\
\hline Moisture $\times$ fuel & 8 & 0.145 & 0.0181 & 0.92 & 0.511 & 0.35 \\
\hline $\mathrm{S}$ & 30 & 0.589 & 0.0196 & & & \\
\hline Total (Adjusted) & 44 & 4.008 & & & & \\
\hline Total & 45 & & & & & \\
\hline
\end{tabular}


Figure 5. Scatter plot of percent of fuel burned vs. mean temperature. Solid circles represent temperature at $5 \mathrm{~cm}$; empty triangles represent temperature at $30 \mathrm{~cm}$. Spearman's rank correlation $\left(r_{\mathrm{s}}\right)$ and $P$-values are given for each set of points.

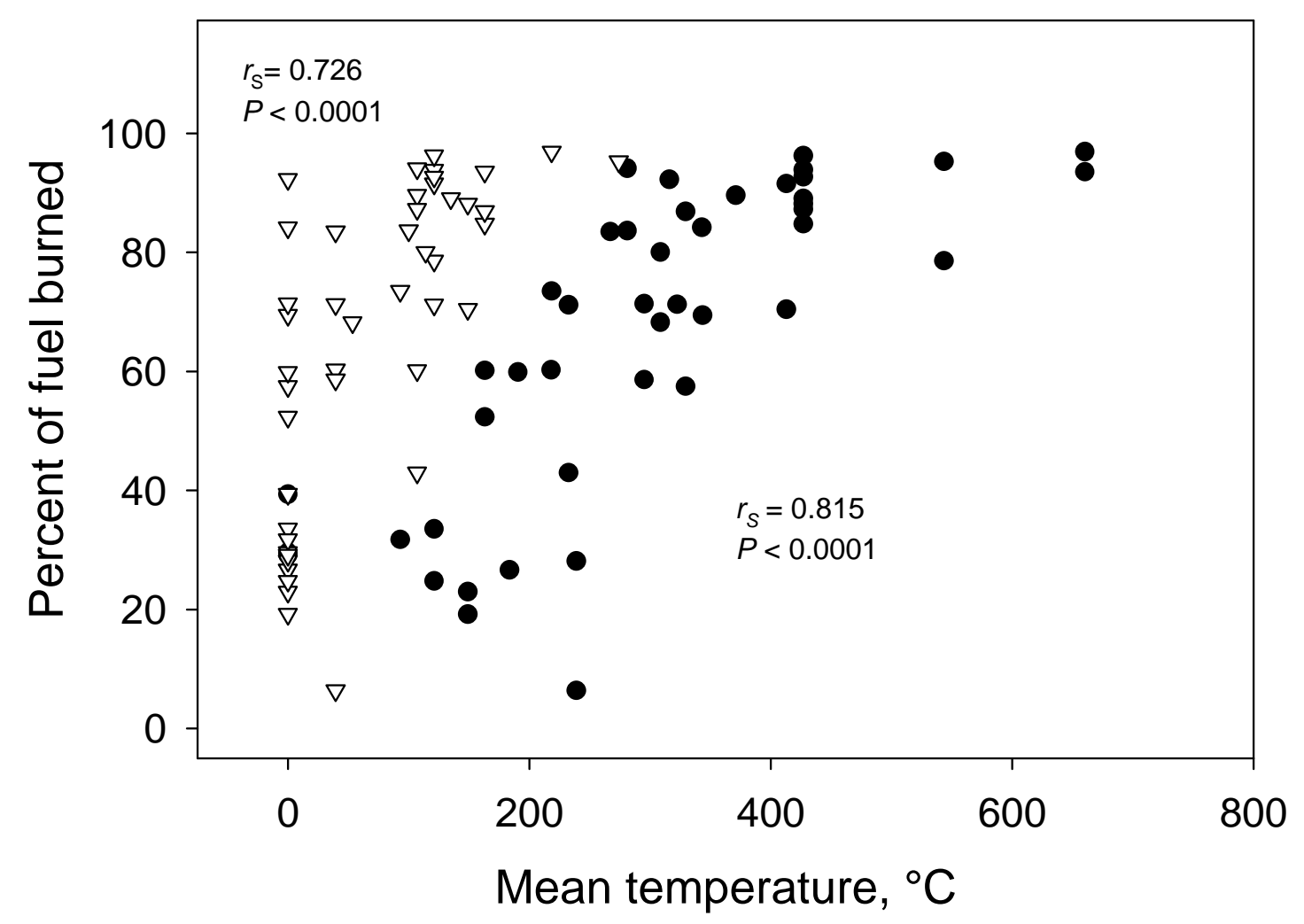

have enough spatial resolution in their experiment to see the temperature extremes that we recorded.

Furthermore, fire behavior will vary over time depending on the specific fuel conditions. Litter mass and depth are at their greatest during the fall and early winter after deciduous trees drop their leaves (Lang 1974; Lang and Forman 1978). Initially, the litter is light and 'fluffy,' but soon compacts and begins to decompose over the winter. During the spring and early summer, litter mass is at the least point for the year. Most of the fluffiness is gone from the litter layer. Fires might tend to burn hotter in fall litter conditions than in spring litter conditions, because the fall-fluffiness will increase the surface area available for combustion. Even though our litter mass estimates were taken during the summer of 2004, the actual litter conditions in our treatments more closely mirrored fluffy, fall litter than compacted, spring litter since we were unable to completely compact litter as it would have been in the spring. Iverson et al. (2004) report the results from burns conducted during March and April (and hence in litter that was fully compacted following winter), thus, it is unsurprising that our temperatures were hotter than theirs.

Two other differences help explain the apparent discrepancy between our results and 
theirs. First, Iverson et al. (2004) used a 25 $\mathrm{cm}$ height for their temperature measurements. Comparing their values to our $30 \mathrm{~cm}$ values indicates much closer agreement in flame temperatures. Temperature tends to decrease with increasing height. Thus, it is unsurprising that our $30 \mathrm{~cm}$ data would correspond to their $25 \mathrm{~cm}$ data more closely than does our $5 \mathrm{~cm}$ data. Second, Iverson et al. (2004) used thicker tags than we used. Since pyrometers do not measure the actual fire temperature, but rather record the temperature that they themselves attained, the additional mass of thicker tags will take longer to heat and will be less sensitive to instantaneous fluctuations in high temperature. Our thinner tags will be more responsive to the actual fire temperature than thicker aluminum tags would be.

High fuel load treatments burned hotter than expected when using Iverson et al. (2004) as a baseline. The maximum temperature sensitivity of Tempilaq $^{\circ} \mathrm{G}$ in our experiment was $427{ }^{\circ} \mathrm{C}$. At $5 \mathrm{~cm}, 24 \%$ of treatment units exceeded this temperature, with 9\% above 660 ${ }^{\circ} \mathrm{C}$. Using additional paints with indicating points within this range $\left(427-660^{\circ} \mathrm{C}\right)$ would have enabled us to see more resolution at the higher temperatures. Finer resolution of temperatures would also have likely allowed for a higher correlation between pyrometer temperature and percent fuel burned. Vertical clumping of temperatures was readily visible at $5 \mathrm{~cm}$ and at $30 \mathrm{~cm}$. Using additional paints with higher melting points would have broken apart these data clumps, causing them to spread laterally and improving the correlation between temperature and percent of fuel burned.

Our study replicated the range of representative fine-fuel conditions found within the landscape of southeastern Ohio mixed-oak forests. Specific fuel conditions in southeastern Ohio vary depending on slope and aspect (Wolfe et al. 1949; McCarthy et al. 2001; Iverson and Hutchinson 2002; Riccardi
2005;), which will lead to substantially different fire behavior in different areas within a prescribed burn unit. In order to truly predict fire behavior for a specific unit within topographically diverse, eastern deciduous forests, managers will need to have spatiallyexplicit information about the fuel loads and fuel moistures present throughout the landscape. Pre-burn fuel assessments will need to take spatial variability into consideration across multiple spatial scales. Fuel moisture measurements will need to be taken in the entire range of fuel loads present.

Our results have direct management applications. Land managers often have specific goals for prescribed fires. For instance, many management prescriptions in eastern mixed-oak forests focus on reducing the density of smaller red maple stems to encourage oak regeneration. Prescribed fires can be used as a tool to remove smaller, undesired stems from a forest, but the impact of a fire on stems will depend on the maximum temperature immediately adjacent to each stem. Bova and Dickinson (2005) found that stem kill of red maple and Chestnut oak (Q. prinus) was primarily a function of fire behavior: temperature, length of exposure to flames, and heat flux over time. By combining their models with our data, a land manager could determine the fuel load and fuel moisture necessary to achieve specific, mortality-inducing temperatures during a burn. Inversely, a manager can predict the level of stem mortality to expect depending on the fuel load and fuel moisture conditions present prior to a prescribed fire. The results of those predictions could be used as a guideline for manipulating the fuels present in a forest in order to accomplish the desired management outcome. Fuel treatments could be conducted at a larger scale (i.e., at stand level) or at a smaller scale (i.e., surrounding individual 'target' trees).

In natural systems, fires tend to be very 'patchy.' Seemingly homogenous fuel 
conditions often produce a mosaic of burned and unburned conditions patches. As fire carries through an ecosystem, some areas burn completely, others are burned mildly, while still others are completely skipped by fires. At a functional level, this inherent patchinessespecially in fires that occur in otherwise seemingly homogenous conditions - is likely related to small differences in fuel load and fuel moisture.

\section{SUMMARY}

Fire behavior is correlated to fuel moisture and fuel load conditions. Percent of fuel burned is correlated to temperature. Fuel load and fuel moisture can be used to predict fire behavior and the resulting mortality of trees and shrubs in an ecosystem. Small differences in fuel moisture and fuel loading can substantially alter fire behavior, and likely influence patchiness of fires in seemingly homogenous conditions.

\section{ACKNOWLEDGEMENTS}

This work was completed as a portion of a MS thesis project for JBG. We would like to thank Drs. Kim Brown, Jim Dyer, and Don Miles for serving on the thesis committee. Financial support was provided by the Department of Environmental and Plant Biology, the Ohio University Graduate Student Senate, and the Ohio Biological Survey. Matthew Albrecht, Kevin Lewis, Ryan McEwan, and Lisa Schelling provided editorial assistance. Lance Glasgow and Doug Christen assistance with litter collection and prescribed fires.

\section{REFERENCES}

Abrams, M. D. 1992. Fire and the development of oak forests. BioScience 42 (5):346-353.

Bessie, W. C., and E. A. Johnson. 1995. The relative importance of fuels and weather on fire behavior in sub-alpine forests. Ecology 76 (3):747-762.

Bova, A. S., and M. B. Dickinson. 2005. Linking surface-fire behavior, stem heating, and tissue necrosis. Canadian Journal of Forest Research 35 (4):814-822.

Braun, E. Lucy. 1950. Deciduous forests of eastern North America. Philadelphia, PA: Blakiston Company.

Brose, P., T. Schuler, D. Van Lear, and J. Berst. 2001. Bringing fire back - The changing regimes of the Appalachian mixed-oak forests. Journal of Forestry 99 (11):30-35.

Brown, R. T., J. K. Agee, and J. F. Franklin. 2004. Forest restoration and fire: Principles in the context of place. Conservation Biology 18 (4):903-912.

Clark, J. S. 1997. Facing short-term extrapolation with long-term evidence: Holocene fire in the north-eastern US forests. Journal of Ecology 85 (3):377-380.

Clark, J. S., P. D. Royall, and C. Chumbley. 1996. The role of fire during climate change in an eastern deciduous forest at Devil's Bathtub, New York. Ecology 77 (7):2148-2166.

Delcourt, P.A. , and H.R. Delcourt. 1998. The influence of prehistoric human-set firest on oakchestnut forests in the southern Appalachians. Castanea 63 (3):337-345. 
Drewa, P. B., W. J. Platt, and E. B. Moser. 2002. Fire effects on resprouting of shrubs in headwaters of southeastern longleaf pine savannas. Ecology 83 (3):755-767.

Forsyth, Jane L. 1970. A geologist looks at the natural vegetation map of Ohio. The Ohio Journal of Science 70 (3):180-191.

Franklin, Scott B., Philip A. Robertson, and James S. Fralish. 1997. Small-scale fire temperature patterns in upland Quercus communites. Journal of Applied Ecology 34 (3):613-630.

Hintze, J. 2001. NCSS. Number Cruncher Statistical Systems, Kaysville, UT.

Hutchinson, T. F., R. E. J. Boerner, S. Sutherland, E. K. Sutherland, M. Ortt, and L. R. Iverson. 2005. Prescribed fire effects on the herbaceous layer of mixed-oak forests. Canadian Journal of Forest Research 35 (4):877-890.

Hutchinson, Todd. F. 2004. Prescribed fire effects on understory vegetation across a topographic moisture gradient in oak forests. Ph.D dissertation, Evolution, Ecology, and Organismal Biology, The Ohio State University, Columbus, $\mathrm{OH}$.

Iverson, L. R., and T. F. Hutchinson. 2002. Soil temperature and moisture fluctuations during and after prescribed fire in mixed-oak forests, USA. Natural Areas Journal 22 (4):296304.

Iverson, L. R., D. A. Yaussy, J. Rebbeck, T. F. Hutchinson, R. P. Long, and A. M. Prasad. 2004. A comparison of thermocouples and temperature paints to monitor spatial and temporal characteristics of landscape-scale prescribed fires. International Journal of Wildland Fire 13 (3):311-322.

Kennard, Deborah K., Kenneth W. Outcalt, David Jones, and Joseph J. O'Brien. 2005. Comparing techniques for estimating flame temperature of prescribed fires. Fire Ecology 1 (1):75-84.

Lang, Gerald E. 1974. Litter dynamics in a mixed oak forest on the New Jersey Piedmont. Bulletin of the Torrey Botanical Club 101 (5):277-286.

Lang, Gerald E., and Richard T. T. Forman. 1978. Detrital dynamics in a mature oak forest: Hutcheson Memorial Forest, New Jersey. Ecology 59 (3):580-595.

McCarthy, B. C., C. J. Small, and D. L. Rubino. 2001. Composition, structure and dynamics of Dysart Woods, an old-growth mixed mesophytic forest of southeastern Ohio. Forest Ecology and Management 140 (2-3):193-213.

McRae, D. J. 1999. Point-source fire growth in jack pine slash. International Journal of Wildland Fire 9 (1):65-77.

Miller, C., and D. L. Urban. 2000. Connectivity of forest fuels and surface fire regimes. Landscape Ecology 15 (2):145-154. 
Onega, T. L., and W. G. Eickmeier. 1991. Woody detritus inputs and decomposition kinetics in a southern temperate deciduous forest. Bulletin of the Torrey Botanical Club 118 (1):52-57.

Pyne, Stephen J., Patricia L. Andrews, and Richard D. Laven. 1996. Introduction to wildland fire. New York, NY: Wiley and Sons.

Riccardi, C. L. 2005. The effect of prescribed fire on fuel loads, seed germination, and acorn weevils (Coleoptera: Curculionidae) in mixed-oak forests of central Appalachia. Ph.D. dissertation, Department of Biological Sciences, Ohio University, Athens, $\mathrm{OH}$.

Sapsis, D. B., and J. B. Kauffman. 1991. Fuel consumption and fire behavior associated with prescribed fires in sagebrush ecosystems. Northwest Science 65 (4):173-179.

Tveten, R. K., and R. W. Fonda. 1999. Fire effects on prairies and oak woodlands on Fort Lewis, Washington. Northwest Science 73 (3):145-158.

Williamson, N. M., and J. K. Agee. 2002. Heat content variation of interior Pacific Northwest conifer foliage. International Journal of Wildland Fire 11 (1):91-94.

Wolfe, John N., Richard T. Wareham, and Herbert T Scofield. 1949. Microclimates and macroclimate of Neotoma, a small valley in central Ohio. Columbus, OH: Department of Botany and Plant Pathology, The Ohio State University.

Zar, Jerrold H. 1999. Biostatistical Analysis. 4th ed. Upper Saddle River, NJ: Prentice Hall. 